\title{
Heat Transfer Performance of a Vertical Thermosyphons Heat Pipe Heat Exchanger using Hybrid Nanofluid for Automobile Engine Exhaust Heat
}

\author{
S. A. Shelke* and N. S. Gohel \\ Sinhgad College of Engineering, Vadgaon Budruk Pune-411041, Maharashtra, India \\ Accepted 15 June 2016, Available online 20 June 2016, Special Issue-5 (June 2016)
}

\begin{abstract}
Waste heat is produced in a process by way of chemical reaction or fuel combustion, and then released into the atmosphere even it is possible that this waste heat can be recycled and reused for other economic and useful purpose. The heat recovering strategy depends on the temperature of the waste heat gases and the economics involved. Direct and indirect benefits are involved in heat recovery. Waste heat recovery has a directly has effect on the performance of the process and indirect benefits involve reduction in pollution, equipment size and auxiliary air consumption. This study concentrates on the recovery of waste exhaust heat from internal combustion engine with higher temperature. The objective of this work is to study thermosyphons heat pipe technology for the heating of fresh air by using recovered heat from engine exhaust and to develop a thermosyphons heat pipe heat exchanger experimental setup. The performance of heat pipe heat exchanger charged with (50\% BN +50\% ZnO) / H2O nanofluid increases with increase in source temperature. Maximum effectiveness and heat gain at condenser section observed for proposed heat pipe heat exchanger is up to 0.18 and $1331.33 \mathrm{~W}$ respectively.
\end{abstract}

Keywords: Automobile waste heat recovery, Thermosyphons, Heat Pipe heat exchanger, Thermal performance, Effectiveness.

\section{Introduction}

Major quantity of hot exhaust gases is generated from Kilns, Ovens, Boilers, and Furnaces. A large amount of primary fuel can be saved, if some amount of this waste heat can be recovered, the energy lost in waste gases cannot be totally recovered. Major of the heat can be recovered and losses are reduces.

\subsection{Exhaust gas engine specifications}

The specifications of 4 stroke engine is shown in table 1

Table 1 Experimental engine parameters

\begin{tabular}{|c|c|}
\hline Manufacturer & Briggs \& Stratton \\
\hline Engine type & Single cylinder,4 stroke SI engine \\
\hline Bore & $79.375 \mathrm{~mm}$ \\
\hline Stroke & 61.9252 \\
\hline Compression ratio & $8: 1$ \\
\hline Capacity & $305 \mathrm{cc}$ \\
\hline RPM & 3600 \\
\hline BHP@3600 & $7.46 \mathrm{KW}$ \\
\hline Cooling system & Air cooled \\
\hline
\end{tabular}

*Corresponding author: S. A. Shelke

\subsection{Thermosyphons heat pipe}

Thermosyphons are heat exchanging devices that circulate a substance through natural convection. In other words, the movement of the coolant occurs due to change in the density of the coolant, without an external source. The change in density of the coolant occurs in thermosyphons applications because of rise in the coolant temperature or phase transition. The portion of the coolant which is less dense rises and the denser portion falls. This phenomenon creates a force which drives the coolant to movement. As the circulation of the coolant occurs naturally, the thermosyphons do not use external surface forces, such as pumps. As the difference in the coolant densities is the driving force for the movement, the thermosyphons is dependent on the gravitational field and thus requires to be placed in such orientation as it is designed.

\subsection{Performance Enhancement of Heat Pipe}

Many people have used threaded tubes, sintered tubes, and finned tubes to increase the contact area in between the internal working fluid and heat pipe, thus improving the thermal performance of heat pipe. Thus, changing the conventional working fluid by a working 
fluid with a high heat transport properties is worth considering.

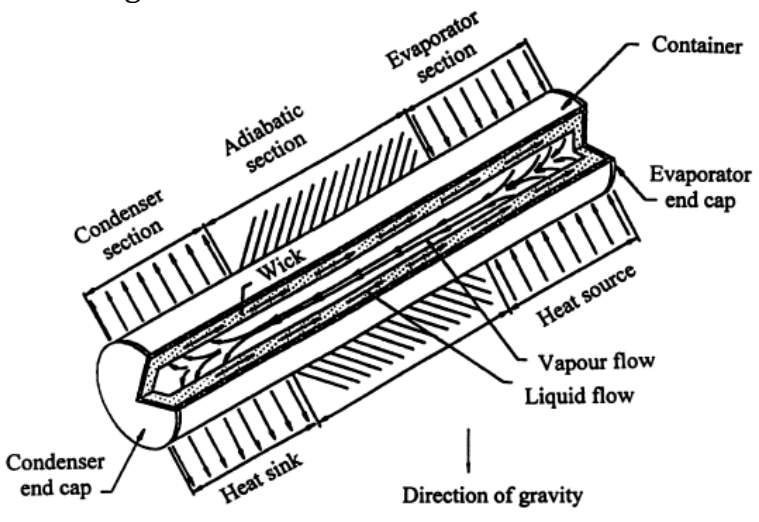

Fig 1: Schematic diagram of heat pipe

Many researchers have stated that heat transfer performance can be improved by using nanofluid in heat exchange applications. By mixing of nanoparticles with the traditional working fluid nanofluid is produced. For further study by using nanofluid in a heat pipe is applicable. The nanoparticles include diamond and oxide particles. The most used types of heat pipes primarily include pulsating heat pipes, twophase closed thermosyphons, and oscillating heat pipes. Nanoparticle shape, material, size, volume concentration, temperature, $\mathrm{PH}$ etc are the parameters affecting thermal performance of nanofluid.

\subsection{Selection of nanofluid}

Many scientists have used the nonmaterial as $\mathrm{CuO}$, CNT, $\mathrm{Al}_{2} \mathrm{O}_{3}, \mathrm{TiO}_{2}$ and results show the enhancement in thermal conductivity. At this stage it is necessary to find the nonmaterial's which gives comparatively same enhancement in thermal conductivity at lower cost with previously used nonmaterial. This results in to the selection of material as mixture of Boron nitride and Zinc oxide $(50 \% \mathrm{BN}+50 \% \mathrm{ZnO}) / \mathrm{H}_{2} 0$. The behavior of variation in thermal properties of nanofluid with particle size suggest that decrease in particle size leads to higher enhancement in thermal properties up to certain extent of particle size. Thus optimum size selected for proposed work is $40 \mathrm{~nm}$ from review of literature.

As mixture of Boron nitride and Zinc oxide nanopowder gives the comparatively nearer thermal conductivity with previously used nanofluid at the same time having low coefficient of friction which leads to reduced pumping power and cost effective. At the same time it comes to know that mass fraction of nanofluid affects on the overall thermal conductivity enhancement of nanofluid. Mass fraction increment of nanofluid gives rise in thermal conductivity but it also increases the friction energy loss i.e. raises in pumping power. It limits the maximum mass fraction.

For proposed work it is decided to select the volume fraction of nanofluid as $2 \%$. Previous researchers have used the mass fraction till $0.5 \%$. By taking the benefit of the reduction in cost for rise in thermal conductivity of nanofluid in proposed work volume fraction selected is $2 \%$.

\subsection{Preparation of nanofluid}

\section{A) Calculation of mass for nanopowder}

1) Volume of Tube.

2) Volume Fraction

3) Volume of Nanopowder

4) Mass of Nanopowder

$$
\begin{aligned}
& \text { 1. Volume of Tube }=\frac{\pi}{4} \cdot d^{2} .1 \\
& =0.116 \times 10-3 \mathrm{~m}^{3}
\end{aligned}
$$

Total Volume of Single Heat pipe is $0.116 \times 10^{-3} \mathrm{~m}^{3}$, but from literature study it is seen that the thermal performance of TPCT is superior at filling ratio $40 \%$. Hence, $40 \%$ of volume of tube $=0.058 \times 10^{-3} \mathrm{~m}^{3}$

\section{Volume Fraction is selected $2 \%$.}

$$
\begin{aligned}
& \text { 3. Volume Fraction }=\frac{\text { Volume of nanopartical }}{\text { Volume of Nanofluid }} \\
& \frac{2}{100}=\frac{\text { Volume of nanopowder }}{0.058 \times 10^{-3}} \\
& \text { Volume of Nanopowder }=2.32 \times 10-6 \mathrm{~m}^{3}
\end{aligned}
$$

4. Mass of Nanopowder for single Heat pipe $=$ Density of Nanopowder X Volume of Nanopowder $=4.872 \mathrm{gm}$.

Hence Total Mass of Nanopowder used in Heat Exchanger $=$ Mass of nanopowder of single heat pipe $\mathrm{X}$ Number of heat pipe.

$$
=38.97 \mathrm{gm} \text {. }
$$

Thus the $38.97 \mathrm{gm}$ of $50 \% \mathrm{BN}+50 \% \mathrm{ZnO}$ nanopowder is added in the $400 \mathrm{ml}$ of water in order to get $(50 \% \mathrm{BN}$ $+50 \% \mathrm{ZnO}) / \mathrm{H}_{2} \mathrm{O}$ nanofluid with $2 \%$ volume fraction.

\section{Literature Review}

Yang et al. studied that, the heat pipe heat exchangers feasibility by using for heating applying automotive exhaust gas is studied and the calculation method is developed. Simple experiments are carried out by using heat pipe heat exchanger is set up for heating HS663, a large bus to study the performance of the heat pipe heat exchanger. He found the experimental results, good agreement with numerical results which indicate the benefit of exhaust gas heating.

Meyer et al. studied on heat recovery on mini dryer he concluded that the heat transfer charge between hot and cold streams of the heat pipe (Thermosyphons) heat recovery of the heat exchanger is accurately predicted by the theoretical model for average temperature difference between the two streams of greater than $15^{\circ} \mathrm{C}$.The experimental evaluation of the heat recovery heat exchanger modified to the minidrier yielded a 32\% saving of R2 321 per annum and 
for the total heat pipe installation cost of R7 469a simple payback period of $7469 / 2321=3.2$ years was obtained. A significantly lower payback period is possible if the heat exchanger be included in the design of the mini-drier as a standard production feature.

Wang et al. investigated a numerical method to analyze the thermosyphons heat exchanger with and without the presence of electro hydrodynamics. The proposed model was used for both unbalanced and balanced thermosyphons heat exchangers. For the unbalanced thermosyphons heat exchangers, it was seen that with increment in the ratio of $\mathrm{Me} / \mathrm{Mc}$ when electro hydrodynamics was applied at the condenser alone the performance improvement increased. For the balanced thermosyphons heat exchanger, the calculated results of heat transfer rate for R-134a and water agreed well with experimental data.

Shang et al. [4] investigated the heat transfer characteristics with $\mathrm{Cu}$-water nanofluids as the working fluid different filling ratios of a closed loop heat pipe and the results were compared with working fluid as the distilled water. From experimental results confirmed it can be said that the in the heat pipe could enhance the maximum heat removal capacity of $83 \%$ by using of $\mathrm{Cu}$-water nanofluids.

Mousa performed an experimental study on an effect of nanofluid in Circular Heat Pipe. The nanofluid consisted of $\mathrm{Al}_{2} \mathrm{O}_{3}$ nanoparticles of a diameter of 100 $\mathrm{nm}$. The experimental data were compared between the nanofluids and DI water consisting the total heat resistances and the wall temperatures of the heat pipe. From experimental results it can be confirmed that the concentration of the nanofluid increasing, and the decrement in thermal resistance of heat pipe.

\section{Development of experimental Set up}

This work aims to investigate the experimental performance of heat pipe heat exchanger charged with Hybrid Nanofluid under variable source temperatures and mass flow rate.

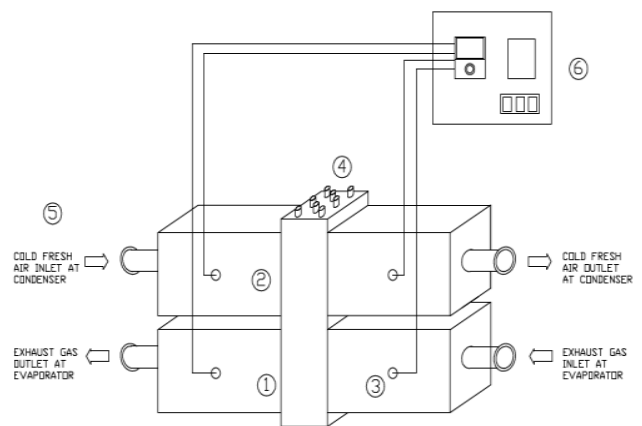

1. Evaporator section, 2. Condenser section, 3. Thermocouples, 4. Heat pipe heat exchanger, 5. Blower, 6. Control Panel

Fig. 2 Schematic diagram of the experimental set up.

With broad perspective this study aims to investigate the feasibility of HPHX from low temperature waste heat source. Heat pipe heat exchangers are devices that made the exchange of energy (waste heat) from a waste heat source to a colder source. Fig. 2 shows the experimental setup diagram of the experimental system. The heat pipe heat exchanger was equipped with ten heat pipes arranged vertically at an angle of $90^{\circ}$.

\subsection{Test Methodology}

To investigate the thermal performance of TPCT heat recovery heat exchanger charged with nanofluid for engine exhaust heat, experimentation is performed by following steps

1) Engine is set at fix throttle conditions. Engine exhaust is reached at steady temperature and exhaust gas is get pass in to the evaporation section.

2) At steady state the hot and cold air stream inlet and outlet temperatures across heat pipe heat exchanger is measured.

3) Air velocity is measured with the help of vane anemometer.

4) Same procedure is followed by varying throttling position of engine and various trials are conducted.

\subsection{Data Reduction}

The heat input, effectiveness of heat exchanger is calculated by the following equations.

Effectiveness of heat exchanger $=Q_{\text {actual }} / Q_{\max }$

Heat Exchanger effectiveness $(\varepsilon)=\frac{\text { Thi-Tho }}{\text { Thi-Tci }} \times 100$

\section{Results and Discussion}

To evaluate thermal performance of heat pipe heat exchanger, thermal characteristics as such Effectiveness $(\epsilon)$, heat gain $(Q)$ and outlet temperature are compared with inlet gas temperature.

\subsection{Calculation of Heat gain (Q)}

At various inlet gas temperatures, supplied by exhaust gases of engine heat gain by air at evaporator section, Heat gain is calculated. Experimentation is performed at $120^{\circ} \mathrm{C}, 125^{\circ} \mathrm{C}, 130^{\circ} \mathrm{C}, 135^{\circ} \mathrm{C}$ and $140^{\circ} \mathrm{C}$.

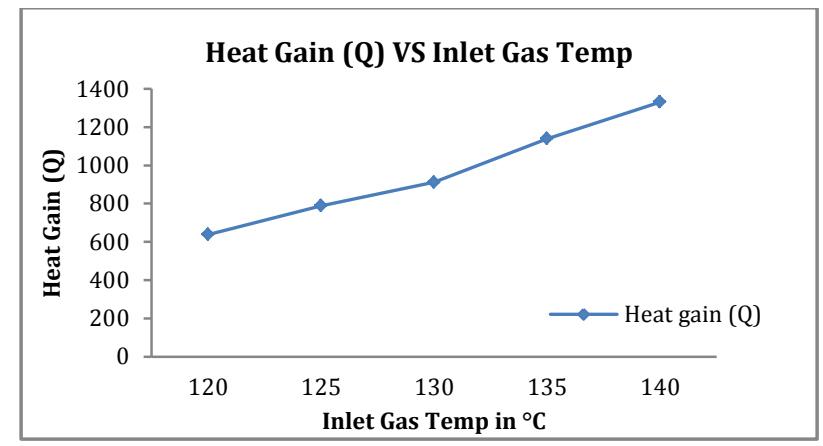

Fig. 3 Heat gain (Q) verses Inlet gas temperature

The above graph of Heat gain verses Inlet gas temperature at exhaust gas temperature shows that heat gain ranges from $638.44 \mathrm{~W}, 788.52 \mathrm{~W}, 911.82 \mathrm{~W}$ $1138.68 \mathrm{~W}$ and $1331.33 \mathrm{~W}$ at $120^{\circ} \mathrm{C}, 125^{\circ} \mathrm{C}, 130^{\circ} \mathrm{C}$ $135^{\circ} \mathrm{C}$ and $140^{\circ} \mathrm{C}$ respectively. 


\subsection{Analysis of Effectiveness $(\epsilon)$}

At various inlet gas temperatures, supplied by exhaust gases of engine heat gain by air at evaporator section, Effectiveness is calculated. Experimentation is performed at $120^{\circ} \mathrm{C}, 125^{\circ} \mathrm{C}, 130^{\circ} \mathrm{C}, 135^{\circ} \mathrm{C}$ and $140^{\circ} \mathrm{C}$.

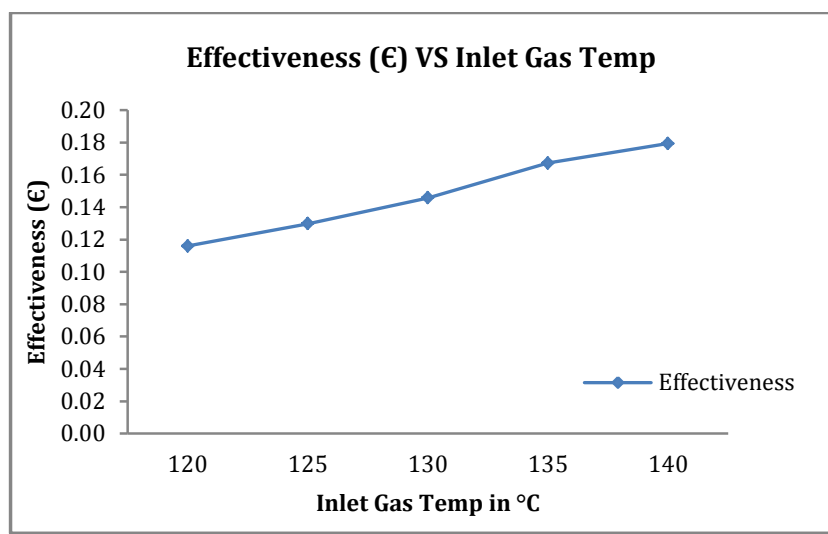

Fig. 4 Effectiveness (Q) verses Inlet gas temperature

The below graph of Effectiveness verses Inlet gas temperature at exhaust gas temperature shows that effectiveness ranges from $0.12,0.13,0.15,0.17$ and 0.18 at $120^{\circ} \mathrm{C}, 125^{\circ} \mathrm{C}, 130^{\circ} \mathrm{C}, 135^{\circ} \mathrm{C}$ and $140^{\circ} \mathrm{C}$ respectively.

\subsection{Analysis of Outlet temperature (Tco)}

The below graph of Outlet air temperature at condenser section verses Inlet gas temperature shows from $38.80^{\circ} \mathrm{C}, 40.08^{\circ} \mathrm{C}, 42.44^{\circ} \mathrm{C}, 45.48^{\circ} \mathrm{C}, 47.70^{\circ} \mathrm{C}$ at $120^{\circ} \mathrm{C}, 125^{\circ} \mathrm{C}, 130^{\circ} \mathrm{C}, 135^{\circ} \mathrm{C}$ and $140^{\circ} \mathrm{C}$ respectively.

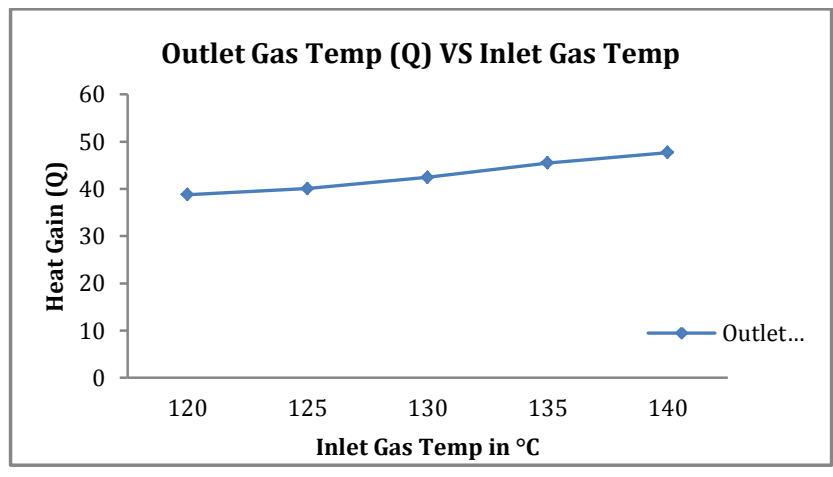

Fig. 5 Effectiveness (Q) verses Inlet gas temperature

\section{Conclusion}

In this study heat recovery by using heat pipe heat exchanger characteristics from exhaust waste heat has been investigated experimentally. The effect of variation in inlet temperature has been investigated. The whole experimentation has been carried out under steady flow condition.

The following conclusions were drawn from this study.

1) Heat gain ranges from $638.44 \mathrm{~W}, 788.52 \mathrm{~W}$, 911.82W, $1138.68 \mathrm{~W}$ and $1331.33 \mathrm{~W}$ at $120^{\circ} \mathrm{C}$, $125^{\circ} \mathrm{C}, 130^{\circ} \mathrm{C}, 135^{\circ} \mathrm{C}$ and $140^{\circ} \mathrm{C}$ respectively.

2) Effectiveness ranges from $0.12,0.13,0.15,0.17$ and 0.18 at $120^{\circ} \mathrm{C}, 125^{\circ} \mathrm{C}, 130^{\circ} \mathrm{C}, 135^{\circ} \mathrm{C}$ and $140^{\circ} \mathrm{C}$ respectively.

3) Outlet air temperature at condenser section verses Inlet gas temperature shows from $38.80^{\circ} \mathrm{C}$, $40.08^{\circ} \mathrm{C}, 42.44^{\circ} \mathrm{C}, 45.48^{\circ} \mathrm{C}, 47.70^{\circ} \mathrm{C}$ at $120^{\circ} \mathrm{C}, 125^{\circ} \mathrm{C}$, $130^{\circ} \mathrm{C}, 135^{\circ} \mathrm{C}$ and $140^{\circ} \mathrm{C}$ respectively.

\section{References}

Feng Yang, Xiugan Yuan, Guiping Lin, (2003),Waste heat recovery using heat pipe heat exchanger for heating automobile using exhaust gas, Applied Thermal Engineering 23, 367-372.

Meyer A, Dobson R., (2006),A heat pipe heat recovery heat exchanger for a mini-drier, Journal of Energy in Southern Africa ,February, Vol. 17.

Wang S., Tiansuwan. J., Kiatsiriroat. T., Wang C.,(2003), Performance analysis of thermosyphons heat exchanger under electric field, Energy Conversion and management. (44), pp.1163-1175.

Shang X., Liu Z., (2008),Heat transfer performance of a horizontal micro grooved heat pipe using $\mathrm{CuO}$ nanofluid, Micromechanics and Micro engineering 18 pp. 35-37.

Mousa M., (2011), Effect of nanofluid concentration on the performance of circular heat pipe, Ains Shams Engineering Journal2, pp. 63-69. 